\title{
Implementasi Aplikasi Penjualan Berbasis Customer Relationship Management untuk meningkatkan loyalitas pelanggan ( Studi Kasus : T.B Gaya Baru )
}

\author{
Ayu Kartika Puspa \\ Program Studi Sistem Informasi \\ Fakultas Ilmu Komputer Universitas Bandar Lampung \\ Jl. Zainal Abidin Pagar Alam No. 26 \\ Labuhan Ratu Bandar Lampung 35142 \\ Email : ayu_kartika_puspa@yahoo.co.id
}

\begin{abstract}
The retail and shopping center showed significant growth and positive contribution to Indonesia's economic recovery. Intense competition makes it difficult for marketers to compete in product innovation. The development of increasingly rapid technological lead new thing will easily be able to be replicated by others, so the role of customer service is important. Customers who are satisfied with the service of the company on an ongoing basis will lead to customer loyalty. CRM (Customer Relationship Management) is a strategy used to get customers (acquire), strengthen relationships with customers (enhance) and retain customers (retain), and services aimed at improving customer satisfaction, operational, analytical, collaborative constitute components CRM.
\end{abstract}

Keywords: Retail, Customer Relationship Managament, Loyalitas

\section{Pendahuluan}

Sektor ritel dan pusat perbelanjaan menunjukkan perkembangan signifikan serta memberikan kontribusi positif dalam pemulihan ekonomi Indonesia. Peluang inilah yang ditangkap oleh pemodal asing yang demikian agresif membangun jaringan ritel di kota-kota besar di Indonesia. Keberadaan pasar tradisional mulai tersaingi atau bahkan tergeser oleh adanya bisnis eceran modern. Menurut Ma'ruf(2005), perkembangan demografi, pertumbuhan ekonomi, perkembangan sosial budaya, kemajuan teknologi, globalisasi, infrastruktur, hukum dan peraturan mempengaruhi pertumbuhan pasar ritel nasional saat ini.

Ketatnya persaingan membuat pemasar sulit untuk bersaing dalam inovasi produk. Sehingga akibatnya, bisnis ritel toko bangunan yang dikelola secara tradisional berubah menjadi bisnis yang semakin inovatif, dinamis, dan kompetitif. Perkembangan teknologi yang semakin cepat menyebabkan sesuatu hal baru dengan mudah akan dapat ditiru oleh orang lain, sehingga peranan layanan konsumen menjadi penting. Suatu hal yang harus diperhatikan dalam persaingan adalah bagaimana setelah konsumen menerima dan merasakan manfaat atau nilai dari suatu produk, konsumen tersebut telah memiliki perilaku loyal, rasa puas dan komitmen terhadap produk tersebut $\operatorname{Mowen}(2002)$.

Menurut Angel(1992), kepuasan maupun ketidakpuasan merupakan penilaian purna pembelian, dimana alternatif yang dipilih sekurangkurangnya sama atau melampaui harapan pelanggan. Pelanggan yang merasa puas terhadap pelayanan perusahaan secara terus-menerus akan membawa kepada loyalitas pelanggan. Menurut Reichheld(1990), loyalitas pelanggan memiliki korelasi yang positif dengan performa bisnis.

Salah satu cara untuk mendapatkan atau mempertahankan pelanggan adalah dengan melakukan Customer Relationship Management (CRM) dengan baik, sehingga hubungan antara pelanggan dengan perusahaan dapat dimulai, dijaga, dan dipertahankan. Menurut Daniel (2009), CRM (Customer Relationship Management) merupakan strategi yang digunakan untuk mendapatkan pelanggan (acquire), mempererat hubungan dengan pelanggan (enhance) dan mempertahankan pelanggan (retain), dan pelayanan yang bertujuan untuk meningkatkan dari kepuasan pelanggan, operasional, analytical, collaborative merupakan komponen-komponen CRM. Penggunaan teori ini diharapkan bisa menyelesaikan permasalahan diatas.

\section{Customer Relationship Management}

CRM berkonsentrasi pada apa yang dinilai oleh pelanggan, bukan pada apa yang perusahaan ingin jual. Pelanggan tidak menginginkan diperlakukan secara sama. Akan tetapi mereka ingin diperlakukan secara individual. Namun, pada dasarnya CRM merupakan suatu cara untuk menganalisa perilaku pelanggan yang dimiliki perusahaan, dimana melalui hasil analisa tersebut, 
perusahaan dapat menentukan cara bagaimana agar dapat melayani para pelanggannya secara lebih personal, sehingga menimbulkan loyalitas pelanggan terhadap perusahaan. Sasaran utama CRM bukan terletak pada kepuasan pelanggan, tetapi lebih mengarah pada loyalitas pelanggan. Maksudnya adalah agar pelanggan tidak hanya puas saat memakai produk perusahaan, melainkan meningkatkan loyalitas pelanggan pada perusahaan. (Strene, 2000).

\subsection{Keuntungan Penggunaan CRM}

Keuntungan dari penggunaan CRM adalah servis yang lebih cepat, mengurangi harga, memperbesar keuntungan, mempunyai rasa memiliki, meningkatkan koordinasi tim, tingkat kepuasan pelanggan menjadi lebih tinggi, meningkatkan loyalitas pelanggan. (Widjaja, 2000)

\subsection{Manfaat dan Tantangan CRM}

Potensi manfaat bisnis dari manajemen hubungan pelanggan sangat banyak. Contohnya, CRM memungkinkan sebuah perusahaan untuk mengidentifikasi serta berfokus pada para pelanggan terbaik mereka, yaitu mereka yang paling menguntungkan bagi perusahaan, agar mereka dapat dipertahankan sebagi pelanggan seumur hidup untuk layanan yang lebih besar dan menguntungkan. Manajemen hubungan pelanggan memungkinkan penyesuaian dan personalisasi realtime atas berbagai produk dan jasa berdasarkan pada keinginan, kebutuhan, kebiasaan membeli serta siklus hidup para pelanggan. CRM juga dapat menelusuri saat ketika pelanggan menghubungi perusahaan, darimana pun titik hubungannya. Sistem CRM juga memungkinkan perusahaan untuk memberi pengalaman yang konsisten dan layanan serta dukungan superior bagi pelanggan, di semua titik kontak yang dipilih oleh pelanggan. Semua manfaat ini akan memberi nilai bisnis strategis bari perusahaan dan nilai pelanggan yang besar bagi para pelanggannya. (O'Brien, 2005)

\subsection{Tiga Fase CRM}

Tiga fase yang dilakukan dalam CRM adalah mengakuisisi pelanggan baru (acquire). Pelanggan baru didapatkan dengan memberikan kemudahan pengaksesan informasi, inovasi baru, dan pelayanan yang menarik. Meningkatkan keuntungan dari pelanggan yang sudah ada (enhance). Perusahaan berusaha menjalin hubungan dengan pelanggan melalui pemberian pelayanan yang baik terhadap pelanggannya. Mempertahankan pelanggan yang menguntungkan (retain). Dengan menawarkan apa yang dibutuhkan oleh pelanggan spesifik bukan yang dibutuhkan oleh pelanggan pasar, karena nilai jasa bagi pelanggan adalah nilai proaktif yang paling sesuai dengan kebutuhannya. Fokus perusahaan saat ini adalah bagaimana mempertahankan pelanggan yang sudah ada pasti memberikan keuntungan bagi perusahaan dari pada bagaimana mendapatkan pelanggan baru yang belum tentu menguntungkan dan loyal terhadap perusahaan. (Kalakota, 2001)

\subsection{Fokus Bisnis pada CRM}

Mengelola berbagai hubungan pelanggan melibatkan dua tujuan yang saling berkaitan : pertama, memberi organisasi dan semua karyawannya yang berhadapan dengan pelanggan, satu pelanggan lengkap tentang setiap pelanggan di setiap hal dan di lintas semua saluran; dan, kedua, memberi pelanggan satu pandangan lengkap tentang perusahaan dan saluran-salurannya yang luas. CRM menggunakan teknologi informasi untuk membuat sistem lintas fungsi perusahaaan yang mengintegrasikan dan mengotomatisasi banyak proses layanan pada pelanggan dalam penjualan, pemasaran, dan layanan pelanggan yang berinteraksi dengan pelanggan perusahaan.

Sistem CRM juga menciptakan kerangka kerja TI software serta database yang dijalankan melalui Web, yang mengintegrasikan proses-proses ini dengan operasi bisnis perusahaan lainnya, dan mendukung kerja sama antara perusahaan dengan para pelanggan, serta mitranya (O'Brien, 2005).

\section{Unified Modeling Language (UML)}

\section{Unified Modeling Language} (UML) merupakan satu kumpulan konvensi pemodelan yang digunakan untuk menentukan atau menggambarkan sebuah sistem software yang terkait dengan objek (Whitten L. Jeffery et al, 2004). Sementara menurut Henderi (2007: 4) Unified Modeling Language (UML) adalah sebuah bahasa pemodelan yang telah menjadi standar dalam industri software untuk visualisasi, merancang, dan mendokumentasikan sistem perangkat lunak. Bahasa Pemodelan UML lebih cocok untuk pembuatan perangkat lunak dalam bahasa pemrograman berorientasi objek $(\mathrm{C}+$, Java, VB.NET), namun demikiantetap dapat digunakan pada bahasa pemrograman prosedural (Ziga Turck, 2007)

UML merupakan salah satu alat bantu yang sangat handal dalam bidang pengembangan sistem berorientasi objek karena UML menyediakan bahasa pemodelan visual yang memungkinkan pengembang sistem membuat blue print atas visinya dalam bentuk yang baku. UML berfungsi sebagai jembatan dalam mengkomunikasikan beberapa aspek dalam sistem melalui sejumlah elemen grafis yang bisa 
dikombinasikan menjadi diagram. UML mempunyai banyak diagram yang dapat mengakomodasi berbagai sudut pandang dari suatu perangkat lunak yang akan dibangun. Diagramdiagram tersebut digunakan untuk (Henderi et al, 2008:71):

1. Mengkomunikasikan ide

2. Melahirkan ide-ide baru dan peluang-peluang baru

3. Menguji ide dan membuat prediksi

4. Memahami struktur dan relasi-relasinya

\section{Use Case Diagram}

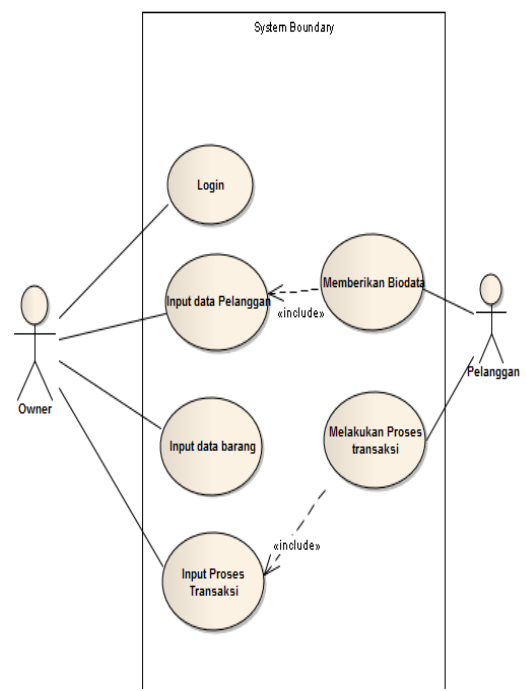

Gambar 1. Use Case Diagram

Di bawah ini gambar class diagram,

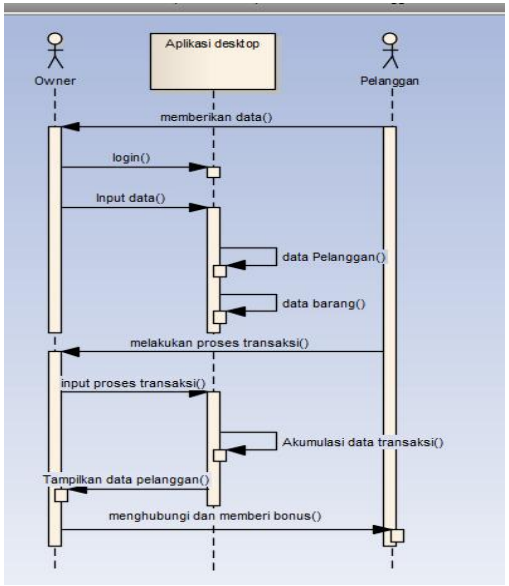

Gambar 2. Class Diagram

\section{Hasil Penelitian}

4.1. Tampilan login

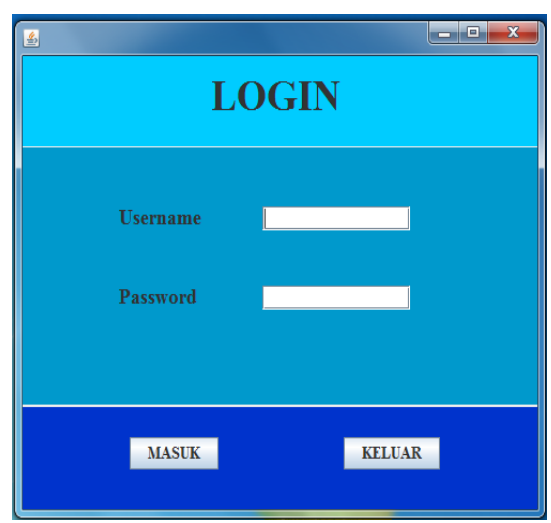

Gambar 3. Tampilan Login

4.2 Form staff atau owner

Di bawah ini gambar form staff,

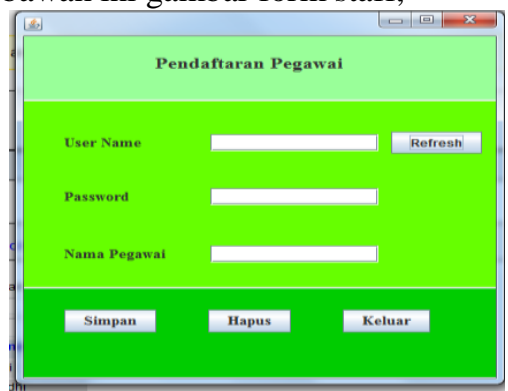

Gambar 4. Form staff

4.3 Form data pelanggan

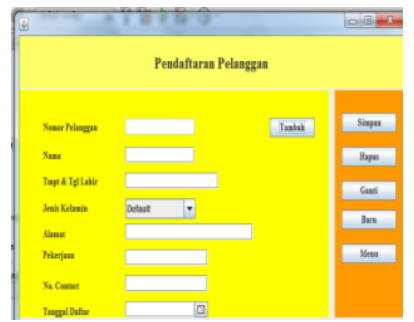

Gambar 5. Form data langganan

4.4 Form jenis/tipe barang

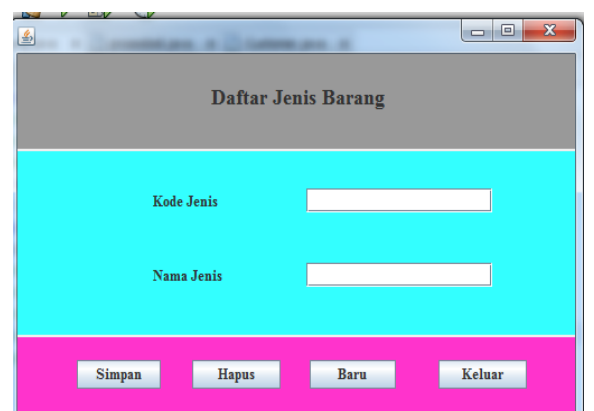

Gambar 6. Form jeni barang 
4.5 Form data item barang

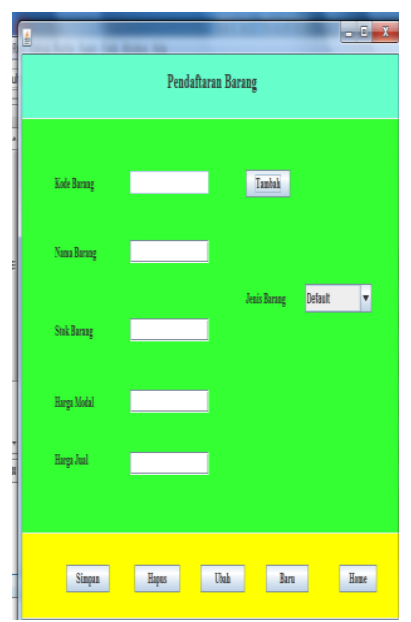

Gambar 7. Form data barang

4.6 Form data transaksi dan Tampilkan data transaksi Pelanggan

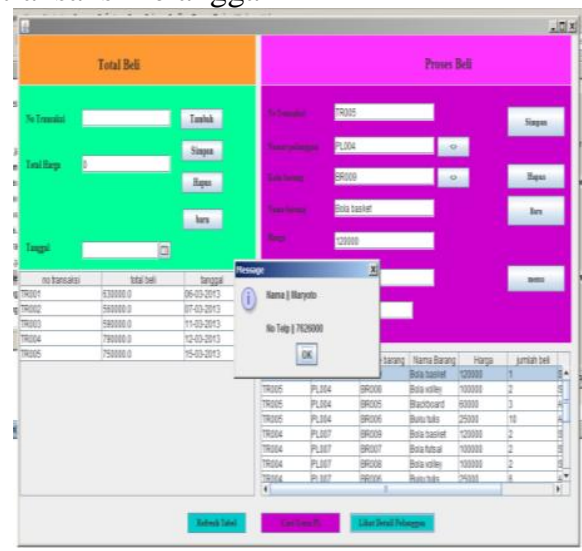

Gambar 8. Form data transaksi

\section{Kesimpulan}

Berdasarkan tugas akhir tentang perancangan aplikasi dekstop berbasis customer relationship managemen untuk meningkatkan loyalitas konsumen, maka kesimpulan yang didapat oleh penulis yaitu;

1. Aplikasi desktop dapat diterapkan dalam usaha retail menjadi sistem yang membantu owner dalam mempertahankan hubungan dengan pelanggan.

2. Dengan adanya aplikasi desktop owner dapat mengambil keputusan dalam memberikan bonus terhadap pelanggan yang datanya sudah tersimpan dalam sistem.

3. Pelanggan lebih tertarik datang ke toko retail Gaya Baru untuk berbelanja berdasarkan hasil kuisioner.

\section{Saran}

Penulis memberikan saran untuk penelitian ini agar dapat dikembangkan lebih lanjut diantaranya:
1.Perlunya penambahan sistem update harga pasar. 2.Perlunya penambahan sistem rekomendasi Item. 3. Perlunya pengembangan sistem dalam bentuk mobile phone.

\section{Daftar Pustaka}

1) Aristoteles Leopold. 2009, Penerapan Customer Relationship Management yang mendukung Multi Channel pada PT. Adira Quantum Multifinance. GunaDarma University, Jakarta

2) Booch,G dan J, Jacobson. 2000, The Unified Modeling Language User Guide

3) Darie , 2008 , Customer Relationship Management : Concept And Tools Elsevier, Science Publishers

4) Dhanta , 2009 , Pengantar Ilmu Komputer, Surabaya

5) Dyche , 2004 , The Customer Relationship Management Handbook, Seventh Edition, USA, Addison, Wesley

6) Jogiyanto , 2005 , Analisis dan Desain Sistem Informasi, Yogyakarta : Penerbit Andi

7) Joni Suhartono. 2012. Analisis dan Perancangan Sistem E-CRM pada toko sepeda BR. Binus University, Jakarta.

8) Messa Asman Atsabani. 2007 , Penjualan Online pada toko alat Olahraga FAY berbasis WEB menggunakan metode CRM. BinaDarma University, Palembang.

9) Nur Heri Cahyana. 2010. Aplikasi Penilaian Kualitas JASA/LAYANAN Retail dengan metode Retail Service Quality dan Analytic Hierarchy Process. UPN "Veteran" Yogyakarta.

10) Turck, Ziga ,2007, Undefined Modeling language Assoc. Prof.,Instambul Technical University, MBA in Contruction Informatics in Contruction Management.

11) Yohannes Yahya. 2012, Pengaruh Customer Relationship Management (CRM) dalam Meningkatkan loyalitas Pelanggan. Budi Luhur University, Jakarta. 